Laboratorio de Arte,4-1991 http://dx.doi.org/10.12795/LA.1991.i04.01

\title{
NOTAS SOBRE LAS EMPRESAS CONSTRUCTIVAS Y ARTÍSTICAS DEL CONCEJO DE SEVILLA EN LA BAJA EDAD MEDIA $1370-1430$ (Y II)
}

por Javier Martínez de AguirRe

En esta segunda parte se abordan otro tipo de encargos constructivos y artísticos del concejo de Sevilla, conocidos por documentación del archivo municipal referente a los años 1370-1430. Se estudian obras en caminos, puentes, abastecimiento y evacuación de aguas, edificios institucionales (casas para reuniones del cabildo, cárcel, casa de la Justicia, mercados), tareas varias (molinos, pavimentación, diques), ayudas a conventos (edificaciones, realización de retablos), pinturas, bordados, etc. En un apartado final se relacionan los maestros que intervienen y las condiciones de su trabajo.

This second article deals with further commissions of construction and artistic work for the Seville Town Council, as described in documents of the Municipal Archive dating from 1370-1430. The study considers projects involving roads, bridges, water-supply and drainage, institutional buildings (chapter-house, prison, court-house, markets), in addition to other public works (mills, paving, dykes), support given to convents (building work, construction of altarpieces), painting, embroidery, etc. The final section lists the craftsmen involved and their working conditions.

Continuamos en este artículo el estudio que, bajo el mismo título, publicó el número 2 de esta revista "Laboratorio de Arte" (1989). En aquella primera aportación nos centrábamos en el sistema de encargos, las murallas y los castillos de Sevilla. Ahora concluimos con otras obras de diversa naturaleza y un breve apartado acerca de los maestros que las realizaron. 


\section{Caminos y puentes}

El cuidado de puentes y caminos absorbía otra importante cantidad de recursos del concejo sevillano, y no sólo en las inmediaciones de la capital, sino a veces a grandes distancias, cuando no había otra institución o persona que los atendiera. La reparación de caminos en las fechas que estudiamos se concentra a partir de 1417, en tanto que las labores en puentes se inician desde los primeros años.

Sin duda, la mayor responsabilidad recaía en la conservación en buen estado del puente de barcas de Triana, por donde entraban a la ciudad gran parte de los suministros. Existió para este fin la figura del "tenedor" del puente, que por razones obvias de maestría recae con frecuencia en el maestro mayor de las atarazanas. Tales fueron Esteban y Pedro Martínez, ocupantes sucesivos del cargo entre 1392 y 1409. La tenencia se convocaba por períodos de diez años y se resolvía como siempre en almoneda en el Corral de los Olmos. Las obligaciones consistían en el compromiso de mantener el puente en buen uso, incluida la sustitución de barcos deteriorados, a cambio de una cantidad anual que en 1400 alcanzaba los $24.000 \mathrm{mrs}$. de moneda vieja; el tenedor garantizaba su buen hacer con una fianza que en 1408 ascendió a 2.000 doblas ${ }^{1}$. Sin embargo, los conflictos entre el concejo y los adjudicatarios de la tenencia fueron muy frecuentes: en 1402 la tenencia estaba embargada y hubo de ser desembargada por la urgencia de las reparaciones; en 1410 y 1425 son los veinticuatros y el mayordomo quienes se responsabilizan de los arreglos a pagar con los fondos de la tenencia; en 1406 las obras no se iniciaban porque el tenedor no quería pagar a los carreteros más de lo estipulado por el condicionado (el eterno problema burocrático) ${ }^{2}$. Más aún, en ocasiones un veinticuatro u otra persona hace de intermediario y controla las obras que urgían al concejo y no se ejecutaban con la adecuada eficacia. No siempre parece corresponder la culpa al tenedor del puente: en 1420 Guillén de Monsalve recibe lo que había adelantado por el alquiler de un almacén para guardar todos los pertrechos para el mantenimiento del puente, almacén que conforme al condicionado Sevilla debía haberle facilitado ${ }^{3}$.

Como viene siendo habitual, los trabajos obedecían a la doble necesidad de conservar y atender las urgencias. La mayor parte de la conservación se sufragaba con el dinero de la tenencia, en tanto que situaciones extraordinarias requerían

1. Como en la primera parte, los documentos aludidos hacen referencia a las publicaciones de $\mathrm{F}$. COLLANTES DE TERÁN: Inventario de los Papeles del Mayordomazgo del siglo XIV. Sevilla, 1968, e Inventario de los Papeles del Mayordomazgo del siglo XV. Sevilla, 1980, que se citarán de manera abreviada como IPM seguido del año correspondiente y el número del documento. IPM 1400, 18 y $1408,9$.

2. IPM 1408,$8 ; 1402,60 ; 1410,7 ;$ y $1425,21$.

3. IPM 1420,49 . 
inversiones cuantiosas. La verdad es que los documentos reflejan estados preocupantes: en 1406 el puente estaba quebrado, en 1410 no se podía pasar y la gran riada de aquel invierno arrastró barcas y puente hasta Coria del Río. En enero se trajo de nuevo a su sitio y entre febrero y noviembre fue necesario disponer cuatro hombres día y noche vigilando la estructura y achicando agua donde fuera preciso, hasta que los carpinteros Juan Fernández y Maestre Abrahem dieron por concluidas las nuevas barcas sustitutorias y la estacada ${ }^{4}$. Sabemos que en 1410 y 1411 los gastos superaron los $50.000 \mathrm{mrs}$. ${ }^{5}$. Otra costosa campaña anterior había sido ejecutada en 1408: se conservan cuentas por más de $75.000 \mathrm{mrs}$. pagados en parte con la tenencia y al menos 35.000 librados específicamente para reparaciones (como siempre, los mandamientos pueden aparecer consignados dos y tres veces: hay tres de $30.000 \mathrm{mrs}$. que creemos corresponden a un único pago) ${ }^{6}$.

Antes de pasar a otros puentes hemos de valorar que el mantenimiento del puente de Triana costó al concejo en el plazo que estudiamos, solamente considerando las tenencias, más de un millón de maravedíes, por lo que ocupa uno de los lugares más altos en la lista de gastos ${ }^{7}$.

El resto de los puentes no pueden compararse con el trianero. La ciudad atendía primordialmente el estado de aquellos más importantes para la vida de Sevilla. A veces actúa ordenando unas obras cuyo costo corría a cargo de los vecinos y moradores del lugar más próximo (puente sobre el arroyo del Cuco en Huévar en 1404) ${ }^{8}$, pero en el mayor porcentaje de casos asume Sevilla la totalidad de los gastos, que podían alcanzar sumas impresionantes, como los 98.500 mrs. en que se adjudicaron al albañil coriano Gónzalo Fernández en 1416 los trabajos en la "Puente Horadada", sobre el río Guadaira camino de Utrera ${ }^{9}$. En ésta y en las demás subastas se siguió el procedimiento habitual con el condicionado y el control subsiguiente de las obras. Una vez más el concejo hispalense procuró que el mayor número de maestros visitara la obra, por si alguno bajaba el presupuesto: antes de las subastas oficiales de la ciudad y, según afirma el documento, todos los maestros albañiles de la misma acudieron al puente, donde fueron obsequiados con vino y fruta ${ }^{10}$. Bien hacían al revisar lo realizado. En 1417 salieron a subasta las obras en el puente sobre el río de Viar en el camino de Cazalla de la Sierra. Tras presentarse el condicionado el 19 de agosto, el 8 de

\footnotetext{
4. IPM 1406,$20 ; 1410,110 ; 1411,47,49$ y 81 .

5. IPM 1410, 206; $1411,47,70$ y varios más.

6. IPM 1407,8 y $1408,53,78$ y 121 . En repetidas ocasiones la madera necesaria se trae del robledo de Constantina.

7. Comparemos por ejemplo con los aproximadamente $34.000 \mathrm{mrs}$. al año gastados en tenencias de castillos y los menos de 600.000 empleados en total en reparaciones de castillos.

8. IPM 1404, 34.

9. IPM 1416, 55.

10. IPM 1416, 71 .
} 
septiembre Diego Alonso, cantero de Triana, las remató en $105.000 \mathrm{mrs}$. ante el corregidor, regidores, jurados y maestros albañiles llamados a la almoneda (aquí también encontramos un pago de $3.300 \mathrm{mrs}$. a los albañiles que hicieron bajas en la subasta) ${ }^{11}$. Sin embargo, las reparaciones resultaron conflictivas. Un debate abierto a causa de dicho puente enfrentó al concejo con la iglesia, al estar construido junto al molino del arzobispo. Los oficiales eclesiásticos declararon la excomunión contra los oficiales de la ciudad en $1419^{12}$. Además, el mayordomo de Sevilla mandó un maestro para vigilar la calidad de la mezcla y la velocidad de ejecución. El resultado fue que el tal Diego Alonso no terminó la obra, por lo que tuvo que devolver una abultada cifra a la ciudad ${ }^{13}$.

Tanto la Puente Horadada como el del Viar o el de Eritaña, adjudicada su reparación en 1419 por $43.000 \mathrm{mrs}$., son excepciones dentro del panorama general. Lo normal es que se aborden labores menores que rara vez superaban los $5.000 \mathrm{mrs}$., si bien son muchas las que no especifican costos. En conjunto, las obras afectaron a los siguientes puentes: alcantarilla de Tablada (1372), puente del arroyo de los Molinos (1381-1382), puente del arroyo del Cuco en Huévar (1404), puente del arroyo de Algarallón entre Aznalcázar y Pilas (1405), puente sobre los caños de Carmona cerca de Torreblanca de los Caños (1412), alcantarilla de Engorrilla camino de Utrera (1422), alcantarilla de los molinos de los Zafarjales camino de Utrera (1422), a los que hay que sumar el de Eritaña en el camino por donde se iba al puente del Guadaira $(1408,1422,1423$ y 1424), puente del Viar (1403, 1417 y 1419) y Puente Horadada (1416). Podrían añadirse a esta relación las barcas que aseguraban el pasaje del río Guadalquivir en Isla Mayor, Villanueva del Camino y Alcalá del Río, acondicionadas por el concejo hispalense. Los maestros que encontramos son los habituales como Alfonso Martínez, Diego Alonso, Diego Fernández, etc., destacando entre ellos el vecino de Coria Gonzalo Fernández, adjudicatario de las obras de Eritaña y Puente Horadada por 43.000 y $98.500 \mathrm{mrs}$. respectivamente ${ }^{15}$.

Por lo que respecta a los caminos, los desvelos se centran en los accesos inmediatos a Sevilla, de los que algo hemos hablado en el capítulo de las puertas, y en los principales de la Tierra de Sevilla. De nuevo encontramos la utilización de columnas, sillares y ladrillos para pavimentación, como en las proximidades

\footnotetext{
11. IPM $1417,40$.

12. IPM $1419,9$.

13. IPM 1419, 23; 1422, 136; tampoco en las obras del puente de Eritaña se utilizaron materiales (cal y ladrillo) de calidad, por lo que hubieron de repararlo de nuevo en 1423.

14. IPM 1419, 10.

15. IPM Tablada 1377-1380, 7; Molinos 1381, 82 IX; Cuco 1404, 34; Algarallón 1404, 10; Torreblanca 1411, 113; Engorrilla 1422, 121; Zafarjales 1422, 165; Eritaña 1407, 129, 1408, 33, 1422, 160, 1423, 11 y 1424, 128; Viar $1403,32,1416,141$ y $153,1417,40,55$ y $113,1418,83,85,1419,9,23,53$ y 1422, 136; Horadada 1415,118 , $1416,5,15,55,71$ y 1418,25 .
} 
de Triana ${ }^{16}$. En los arreglos alejados de la ciudad deben contribuir las localidades cercanas: en 1417 se reparan el camino de las Presas y el puerto de la Higuera con la colaboración de los vecinos de Cumbres Mayores, Fregenal, Cumbres de San Bartolomé y El Bodonal ${ }^{17}$. Es interesante señalar que en la segunda obra es el ermitaño de la ermita vecina del camino quien se encarga de la obra, continuando así una extendida costumbre medieval que incluso había llevado a la santidad a personajes como San Juan de Ortega o Santo Domingo de la Calzada. Pocas veces se abrieron trazados nuevos como el que la riada propició en el camino real de Sevilla a La Rinconada en $1418^{18}$. Probablemente el mayor empeño entre los analizados estuvo en las labores del camino de Sanlúcar la Mayor desde 1426, adjudicadas al albañil de Triana Nicolás Martínez, en que se gastaron al menos 7.490 mrs., como se ve escasa cuantía si lo comparamos con obras de otra naturaleza ya reseñadas ${ }^{19}$.

\section{Obras hidráulicas: conducciones y canalizaciones}

Las obras hidráulicas competencia del concejo de Sevilla servían a una doble finalidad: cuidaban de mantener el abastecimiento de agua potable y procuraban la rápida evacuación de aguas sobrantes de lluvias o inundaciones a fin de evitar charcos y lodazales. En menor medida se preocupaban de canalizar arroyos y lagunas que por su cercanía afectaban a la vida ciudadana.

Es bien sabido que el caudal de agua potable más importante que llegaba a la ciudad procedía del acueducto conocido como Caños de Carmona, que con origen en Alcalá de Guadaira entraba por la puerta de Carmona. Los trabajos efectuados en los caños en el plazo que estudiamos se centran en su mantenimiento en buen uso ${ }^{20}$. Para ello contaba el concejo con dos albañiles cañeros, que cobraban 1.500 mrs. anuales cada uno. Como señala A. Collantes de Terán solían ser mudéjares y parece que cumplían bien su obligación ${ }^{21}$. Los maestros Hamete y Abrahem el Zarco ocuparon el cargo entre 1400 y 1413; a partir de la muerte de Hamete en 1414 le sustituyó otro moro, Maestre Bucar, y durante un

16. IPM 1416,93 y 129.

17. IPM 1417,79 y 119 .

18. IPM $1418,17$.

19. IPM 1425,44 y $61 ;$ y $1427,27$.

20. Consciente del costo que suponía la consetvación de sus conducciones en buen estado, el mismo Alfonso $X$ había impuesto condiciones al concejo y le había asignado para sufragarlo las rentas de catorce molinos en el Guadaira unidas a 1.000 mrs. del real almojarifazgo de la ciudad: J. GONZÁLEZ: El repartimiento de Sevilla. Madrid, 1951, vol. I, p. 477. Sobre la localización de posibles restos medievales: A. JIMÉNEZ: Los caños de Carmona, documentos olvidados, en "Historia, Instituciones, Documentos". Sevilla, n. 2 (1975), pp. 319-328.

21. A. COLLANTES DE TERAN: Sevilla en la Baja Edad Media. La ciudad y sus hombres. Sevilla 1984, p. 84. 
corto período colaboró además otro Maestre Abrahem. Después de 1419 cobraron otros 1.000 mrs. más al año por cuidar el caño que iba de la puerta de Carmona al pilar de la Plaza de San Francisco. En la década de los veinte aumentan el salario y el número, pues encontramos a tres moros cañeros: Hamete Agudo, Hamete de Hornachos y Zaide. Quizá sea interesante señalar el incidente de 1412, cuando, ante la orden del rey obligando a que judíos y moros viviesen apartados de los cristianos y cesasen en sus oficios, el concejo los sustituyó por los albañiles cristianos Lope Martínez y Fernán Ibáñez Guijarro. A los tres meses, la derogación de la orden real restituyó a los moros en su trabajo, con el consiguiente beneficio para la ciudad debido a que otras ocupaciones habían impedido a los cristianos ocuparse como debían, de modo que llegó a faltar agua en el alcázar ${ }^{22}$. Su labor se concentraba fundamentalmente entre el molino de la Alcobilla y la ciudad. Para el primer tramo, en las inmediaciones de Alcalá de Guadaira, existía un encargado de limpiar caños y lumbreras, es decir, los respiraderos y registros de toda conducción de que ya habla Vitruvio. De 1408 a 1418 fue Juan García Bondaño el responsable desde donde nace al agua hasta las últimas lumbreras llamadas "de los ojos"; la tarea no debía ser costosa pues sólo recibe $300 \mathrm{mrs}$. por año ${ }^{23}$.

En ocasiones las reparaciones fueron muy importantes, sobre todo las de 1389 en que se alzaron ciento tres "sobrearcos nuevos", con el empleo de 246.500 ladrillos por un costo total de $66.200 \mathrm{mrs}$., y la de 1393 en que varios arcos y un puente (355.000 ladrillos) sumaron más de $76.000 \mathrm{mrs} .{ }^{24}$. Junto a ellas destacan otras dos: las de los caños y la alcantarilla que salvaba el acueducto junto al cortijo de Hernán Cebolla (obras en 1400, 1402, 1406 y 1407 por valor de más de 30.000 mrs.) y las de varios tramos ejecutadas en 1422 por Maestre Zaide el Castellano por $34.000 \mathrm{mrs} .{ }^{25}$. Aparte hay que añadir las numerosas intervenciones menores, ya que cuando el descuido no se remediaba los caños quedaban "quebrados y ciegos por la mucha suciedad que en ellos había", de modo que no llegaba agua ni a la ciudad ni a los alcázares, y tampoco se movían los moli$\operatorname{nos}{ }^{26}$.

Ya dentro de la ciudad, la conducción más interesante de comienzos del siglo $\mathrm{XV}$ es la realizada para traer agua desde el hospital de la puerta de Carmona al monasterio de San Francisco y la plaza aneja. Parece ser que los franciscanos

22. IPM 1412, 108. Se conservan casi todos los pagos anuales a los cañeros a partir de 1400: por ejemplo 14001401,$31 ; 1414,91,92$ y $97 ; 1419,85 ;$ y 1421,75 .

23. IPM 1407,195 y varios más similares.

24. R. CARANDE: Sevilla, fortaleza y mercado. Sevilla, $1972\left(2 .{ }^{3} \mathrm{ed}\right.$.), pp. 202-206.

25. IPM 1402, 82, 90, 142 y 144; 1406, 157; y 1422, 85, 90 y 91. Se siguió como siempre el sistema de almoneda a la baja: la obra se había rematado primero en 39.000 , pero sucesivas bajas de varios maestros llevaron al precio final de 34.000 , a los que se añadieron los 700 mrs. prometidos a quienes había hecho las bajas.

26. IPM 1404, 53. 
habían obtenido tiempo atrás, por privilegio del rey Fernando III, poder tomar agua para su convento; pero no bastaba la voluntad: había que preparar la conducción. Fue Juan II quien, al conceder agua para un pilar en la plaza de San Francisco destinada a los vecinos, permitió que la traída común sirviera a ambas comunidades. La obra se iba a ejecutar en 1412 por un importe de $68.000 \mathrm{mrs}$, pero al final el cambio en el condicionado retrasó los trabajos tres años hasta que, en agosto de 1415, el moro cañero Maestre Bucar, que estaba encargado de los caños de Carmona, y el albañil Alfonso Martínez se llevaron el contrato y dejaron la obra terminada, con sus cañerías, aljibe, pila de agua limpia, pila mayor y barras de hierro protectoras ${ }^{27}$.

Por lo que respecta a las canalizaciones de aguas sobrantes, Sevilla contaba con un sistema de caños o husillos que regulaban las lagunas interiores y aseguraban la evacuación de sobrantes. Al cuidado de estos husillos, sobre todo día y noche cuando llovía, figuraba igualmente un encargado, que fue entre $1400 \mathrm{y}$ al menos 1423 el carpintero Bartolomé Martínez por 600 mrs. anuales. El mismo obtuvo en almoneda obras relacionadas, como la que en 1413 ascendió a 4.500 mrs. (caños de San Clemente, Triana y Pajería) ${ }^{28}$. Los caños de esta naturaleza se repartían por todo el perímetro y con mayor frecuencia en el lado del río. En ocasiones se especifica su emplazamiento: los de San Clemente que drenaban la laguna de la Feria, los de Huerta de Goles, puerta de Triana, calle Catalanes a la Pajería, laguna y puerta del Arenal, puerta de Minjoar, San Bartolomé el Viejo, calle Calería a puerta de Carmona, Santa Lucía a puerta del Sol; a los que se añaden otros en el interior como los de Santa Marina, Caño Quebrado o San Martín. Normalmente las reparaciones ejecutadas en ellos son de escasa importancia. Incluso puede ser mayor el daño derivado de su reparación que ésta misma, como cuando al subsanar el hundimiento de parte del caño de San Clemente cayeron las tapias del hospital inmediato, que hubo que volver a levan$\operatorname{tar}^{29}$. En algún caso los vecinos de las calles cercanas tuvieron que colaborar en el pago de las obras ${ }^{30}$.

Para terminar, las canalizaciones exteriores más señaladas fueron las del arroyo del Tagarete en 1409, en cuyo ahondamiento desde la torre del Oro a la puerta del Osario se gastaron más de $120.000 \mathrm{mrs}$. procedentes de una contribución

27. IPM 1412, 10,11,84; 1415, 56, 58, 59, 61; 1416, 23, 88, 111, 143, 149; y 1417, 117. Por su importancia hubo un "obrero" específico en estas obras.

28. IPM 1400-1401, 62 y 1423, 73 son los del límite temporal; conservamos además noticias de muchos otros años. La obra de 1413 en el $\mathbf{n} .^{2} 30$ y 81 .

29. IPM 1402, 123 y 1403, 23, 25 y 26. Sí merecen destacarse las de los caños de la laguna que sumaron en 138916.000 mrs.: R. CARANDE: Sevilla. fortaleza y mercado. Sevilla, $1972\left(2{ }^{*}\right)$, p. 203 . Más sobre alcantarillado medieval en A. COLLANTES DE TERÁN: Sevilla en la Baja Edad Media. La ciudad y sus hombres. Sevilla, 1984, pp. 85-87.

30. IPM 1426, 79. 
específica repartida entre el vecindario, que además tuvo que colaborar con peones; y la de la laguna real de Tablada, cuyos cauces de entrada de agua fueron alterados en $1426^{31}$.

Como hemos visto, toda la documentación se refiere específicamente a la ciudad de Sevilla. Solamente una noticia habla de otras localidades: la licencia que se concede al concejo de Fregenal para que repare la fuente de Miranda, cuyas obras, por supuesto, deberían ser sufragadas por los vecinos y moradores ${ }^{32}$.

\section{Edificios institucionales y mercantiles}

Abrimos ahora un apartado en el que abordaremos la construcción y mantenimiento de edificios destinados al alojamiento de instituciones ciudadanas, concretamente las casas del cabildo, las casas o corrales de la Justicia y la cárcel del concejo.

Es bien sabido que antes de la construcción del actual ayuntamiento, el cabildo municipal se reunía en unas casas que, propiedad del cabildo catedral, se abrían al llamado corral de los Olmos junto a la seo. Las noticias referentes al plazo estudiado se centran, además del pago anual de 300 mrs. por alquiler de cierta parte, en la mejora de su habitabilidad (reconstrucción de la bóveda arruinada en 1406; reparación de puertas y mobiliario; construcción de una "necesaria", es decir, un retrete, en 1413 aprovechando espacio de una cuadra pequeña; o revisiones de tejados) ${ }^{33}$. Revistió cierta entidad la edificación de un portal nuevo ante la casa, portal que llevó a cabo el carpintero Antón Rodríguez por 18.900 mrs. a partir de noviembre de 1412 , fecha resolutoria de la preceptiva subasta. Destaca el hecho de que para la obra se adquirieran del corredor de la aduana ocho fustes de mármol, dos de ellos partidos, y de otro particular capiteles y basas, todo ello por $7.260 \mathrm{mrs}$. Tres años más tarde el mismo carpintero se hizo cargo de la ampliación del portal, terminada en sus aspectos finales de pintura y adecentamiento en 1417. No hay que confundir estas labores con otras más a fondo inspiradas en el alcázar real ejecutadas en la década de 1430 y que rebasan el plazo que nos hemos marcado ${ }^{34}$. Pese al traslado del cabildo concejil al nuevo

\footnotetext{
31. IPM $1409,37,48,49$ y $57 ;$ y $1426,57$.

32. IPM 1414,9 .

33. IPM 1404, 100 y 101; 1405, 65; 1407, 174; 1413, 61; 1416, 144; 1430-1431, 68. En 1430 se sustituyen las puertas porque las anteriores habían sido quemadas: 1430-1431, 45. Según C. López Martínez el edificio era propiedad del cabildo, como se deriva de una permuta efectuada en 1568 , y el alquiler se pagaba por el portal. F. COLLANTES DE TERÁN: El patrimonio monumental y artístico del Ayuntamiento de Sevilla. Sevilla, 1967, p. 9, afirma que el edificio pertenecía al cabildo catedral.

34. IPM $1412,119,121 ; 1414,16,37,86,104 ; 1415,60 ; 1416,58,122,144$ y 145.
} 
ayuntamiento en el siglo XVI, el portal cuya realización hemos reseñado u otro similar se mantuvo en pie hasta finales del siglo XVIII, dando paso a dependencias entonces utilizadas como Sala y Antesala de Rentas y Juzgado de la Santa Iglesia, tal y como vemos en el plano de 1781 publicado por T. Falcón. Pese a lo detallado del mismo, no podemos constatar la permanencia de los ocho fustes de mármol, pues su número no cuadra con el de soportes del portal ${ }^{35}$.

La cárcel del concejo también fue objeto de mejoras en esta época. Además de la referencia estudiada por C. López Martínez alusiva a importantes obras por encargo de Guiomar Manuel en 1418, sabemos que en el primer tercio del siglo $\mathrm{XV}$ se construyeron o repararon unas letrinas abovedadas (1403), el portal donde vivía el carcelero (1403-1404), otro portal cercano (1409), una capilla nueva donde pudiese celebrarse misa a los presos (1411), un calabozo (1413), un portal sustitutorio para que juzgasen los alcaldes mientras se labraba la casa de la Justicia (1425) y varias paredes caídas ${ }^{36}$. Normalmente no significaron grandes gastos (4.500 mrs. para el calabozo por ejemplo), excepto la encargada a Juan González de la Cuadra de 1428 que alcanzó 28.000 mrs. El edificio se localizaba en el inicio de la actual calle Sierpes junto a la plaza de San Francisco.

Parecidas son las mejoras realizadas por las mismas fechas en la casa o corral de la Justicia, en la plaza de San Francisco, puesto que aquí también se construye una "cámara necesaria" en 1407 y se reparan dependencias caídas a veces con altos presupuestos: $21.000 \mathrm{mrs}$. en 1415 , casi 20.000 en $1420^{37}$. Con posterioridad a una ampliación de 1421, en 1426 deciden la progresiva remodelación que hizo trasladar las audiencias a edificios cercanos. Por primera vez, aparte de las mencionadas columnas de la casa del cabildo, encontramos referencias claras que hablan de preocupación concreta por el adorno de las construcciones, ya que al final de las obras existe un pago al pintor Diego López por pintar las alas de las casas y por la compra y colocación de azulejos en paredes y ventanas; añadamos nuestro conocimiento de que tradicionalmente en el poyo bajo el portal estaban pintadas las armas del rey ${ }^{38}$.

El carácter de gran mercado que ha sido siempre una seña de identidad de la ciudad conllevaba una serie de obligaciones para el concejo, a fin de que los lugares de intercambio estuviesen en buenas condiciones. Estas dependencias se emplazaban dispersas por la ciudad, predominantemente en las inmediaciones de las puertas y en los espacios que habían sido mercado en época musulmana, en

35. T. FALCÓN, Planos urbanísticos del corral de los Olmos y su entorno, en "Homenaje al Dr. Muro Orejón", Sevilla, 1979, pp. 247-256. Reproducción fotográfica del plano en A. JIMÉNEZ, T. FALCÓN, A. MORALES y M. TRILLO: La arquitectura de nuestra ciudad. Sevilla, 1981, lám. 2 de la ciudad barroca.

36. C. LÓPEZ MARTÍNEZ: Historia de la cárcel de Sevilla. Madrid, s. f., p. 100. IPM 1403, 17 y 27; 1408, $101 ; 1410,182,1412,148 ; 1425,83, \mathrm{XXV}$.

37. IPM 1406,$118 ; 1410,127 ; 1415,38 ; 1420,69 ; 1424,12 ;$ y 1426,93 y 94.

38. IPM 1425, 7, 8, 46, 47, 48, 49, 60, 62, 79 y 81; 1427, 31. Azulejos 1425, 83, XL. Pinturas 1401, 55. 
concreto junto a la catedral y El Salvador, es decir, junto a las antiguas mezquitas principales. Las obras constructivas en estos ámbitos nunca fueron importantes, rara vez superan los $2.000 \mathrm{mrs}$., pero sí frecuentes. En algunos casos, como en la alhóndiga, se centran en ampliaciones repetidas (hay datos de una en 1402 y otra en 1405) ${ }^{39}$. El mayor número son reparaciones de paredes, cubiertas, puertas, casas de los guardas, etc. Los edificios afectados fueron: la alhóndiga; la alcaicería frente a la puerta del Perdón de la catedral; la alcaicería de la seda; la alhóndiga de la sal, cuyo almacén alzado en 1391 costó 30.725 mrs.; la casa de la guarda de los especieros; y las construcciones de madera en que se vendía la caza junto a San Isidoro, el pescado en el Arenal o se reunían las vacas ante la puerta de Carmona ${ }^{40}$.

\section{Noticias constructivas diversas}

El concejo debía atender a gran número de tareas constructivas muy variadas que no soportan fácilmente un encasillamiento ordenador. Plasmaremos aquí un breve panorama.

Si muchos de los edificios que hemos visto respondían a necesidades perentorias, no lo era menos la obtención de dinero mediante rentas. Un grupo interesante componen las labores en los molinos, normalmente sufragadas por los arrendatarios pero que competían al municipio en casos concretos. El concejo pagaba reparaciones cuando los beneficios del molino integraban tan sólo una parte de la renta, pero no siempre cuando era la explotación del molino lo único arrendado ${ }^{41}$. Conocemos numerosos molinos de Sevilla en los que se realizaron obras: además de los de los caños de Carmona, el de Tejada (molino Chequillo), los de Fregenal, Alcalá de Guadaira (la Jara, la Alcobeiba y los Zafarjales junto a los caños de Carmona), etc. En ocasiones los gastos fueron elevados, como los 25.000 mrs. en que remató Diego Rodríguez las labores en los de los caños de Carmona en $1431^{42}$. Las intervenciones tenían lugar en relación con lo saneado de las rentas que obtenía de ellos el concejo: por citar un ejemplo, la de estos mismos molinos ascendía a más de 50.000 mrs. anuales hacia $1410^{43}$.

\footnotetext{
39. IPM 1402,85 y 1405,85 .

40. IPM alhóndiga: 1402,$128 ; 1405,85 ; 1406,108 ; 1422,134 ; 1424,127$; alcaicería 1428,49 y 50, 1429, 83 y 84; alcaicería de la seda $1405,15,1411,82$; alhóndiga de la sal 1405, 102, 1417, 82, 98 y 103; especieros 1406, 33; caza 1411,77; pescado 1402, 47 y 1403, 122; vacas 1420, 12 y 13. Este tipo de obras eran de responsabilidad municipal en casi todos los concejos españoles: V. LAMPÉREZ: Las ciudades españolas y su arquitectura municipal al finalizar la Edad Media. Madrid, 1971, p. 50; incluso podía ser obligatoria, como sucedía con las alhóndigas de Castilla, p. 52.

41. IPM 1417, 132.

42. IPM $1430-1431,3$ y 29 .

43. IPM 1412, 197.
} 
La pavimentación de las calles era tarea acometida sólo en arterias de gran tráfico en la ciudad. Pocas veces se realizaba de manera cuidadosa mediante enladrillado de canto, mientras que en otras ocasiones se acudía al rellenado con ripios que simplemente evitaba los lodazales ${ }^{44}$. En 1416 el concejo decidió cerrar las calles de la Mancebía cerca del río, para evitar escándalos y molestias, y guardar a las mujeres que en ella estuviesen. Primero se colocó una red de hierro que fue sustituida por una puerta también de hierro; la obra fue presupuestada en $13.200 \mathrm{mrs}$. Sin embargo, la medida no debió gustar porque en 1420 ya hubo que sustituir las puertas ${ }^{45}$.

En 1425 se dispuso un dique en la prolongación de la esquina noroccidental de la muralla, junto a la Almenilla, compuesto por una empalizada de madera y cuatro mil cargas de piedra, para aminorar la fuerza de las crecidas ${ }^{46}$.

También eran competencia del concejo las máquinas o ingenios que intervenían en la carga y descarga de mercancías traídas en barco. El "ingenio" por antonomasia se alzaba junto a la puerta de su nombre; otro había junto a la de Bibarragel que fue reparado en 1417 y 1418 ; hay noticias de la construcción de uno hacia 1386 cerca de las atarazanas con un costo de 15.000 mrs. ${ }^{47}$.

Construcciones de madera encargadas por Sevilla eran las horcas, situadas en los caminos y a las puertas de la ciudad, así como en algunas plazas (San Francisco y la Alfalfa) ${ }^{48}$, los palenques que limitaban el lugar para el público durante las audiencias a las puertas del alcázar ${ }^{49}$ y los palenques, cámaras, andamios, empalizadas y tablados necesarios para justas, lidias de toros y otros festejos motivados por la venida de miembros de la familia real, nacimiento de infantes, etc. ${ }^{50}$.

Terminaremos con dos aspectos concretos. Tenemos varias referencias a labores realizadas para compensar daños a terceros, tanto originados por tareas constructivas de la ciudad (en 1406 hubo que reparar las tapias de la huerta de los clérigos caídas al sacar cascajo para diversas obras), como por mal estado de caños o muros (el agua que rebosaba del caño Quebrado derribó unas paredes en 1408), e incluso por las tareas de la justicia (en una persecución de malhechores fueron dañados paredes y tejados en 1424) ${ }^{50}$. Por último, conocemos asimismo la concesión de licencias para construcciones fuera de Sevilla que pudieran alte-

\footnotetext{
44. IPM 1419, 111 en la calle de la Mar; 1423,85 en la calle de la Alhóndiga. Sobre pavimentación medieval: A. COLLANTES DE TERÁN: Sevilla en la Baja Edad Media. La ciudad y sus hombres. Sevilla, 1984, pp. 81-83.

45. IPM 1416, 51, 53, 137;1417,89, 133; 1418, 88;1419, 48, 124; y $1420,75$.

46. IPM 1425, 109 y 111 . Se hizo con reparto de las cargas de piedra entre barrios y collaciones.

47. IPM 1384-1386, 143; 1416, 152; y 1418, 21.

48. IPM 1407,$212 ; 1416,33$ y $142 ; 1419,123 ;$ y $1422,127$.

49. IPM 1420,106 y 131 .

50. IPM tapias 1404, 32; caños 1407, 124; persecución 1424, 50; tejados rotos por los que acudían a ver las lidias de toros 1409, 45; construcciones para festejos son muy numerosas, por ejemplo 1404, 84 y 1407, 203 y 204.
} 
rar las rentas que se recibían en ciertas localidades: un molino en Castilblanco, una carnicería en Fregenal y un horno en El Pedroso ${ }^{51}$. Resulta curioso ver que ya en 1410 hubo que derribar arcos, pisos altos y miradores de ciertas casas que impedían el normal desarrollo de las procesiones en la calle Placentines ${ }^{52}$.

\section{Colaboración con instituciones religiosas}

Entre los gastos fijos de la ciudad había que consignar las cantidades entregadas a determinadas capillas, iglesias y conventos en concepto de limosna o en razón de privilegios concedidos por los monarcas. Así estaban asignados a los responsables de la Capilla de los Reyes de la catedral $18.080 \mathrm{mrs}$. anuales, y a los conventos de Santa Clara, San Clemente y San Leandro $1.000 \mathrm{mrs}$. por año a cada uno. Estas donaciones, de las que conservamos reiteradas noticias, no deben vincularse a obras artísticas concretas, sino al mantenimiento de las instituciones y a la celebración de oficios litúrgicos ${ }^{53}$. Similar finalidad tuvieron los 3.000 mrs. destinados a los cartujos de Santa María de las Cuevas en $1410^{54}$. En algún caso las limosnas se orientaban a colaborar en la celebración de capítulos provinciales de mendicantes (4.000 mrs. para el de franciscanos de 1411 y 3.000 para el de dominicos de 1421) que tampoco implican consecuencias artísticas ${ }^{55}$. En cambio, las remuneraciones destinadas a famosos predicadores podían incrementarse para destinos concretos, como los 2.000 mrs. dados al guardián de los franciscanos para ayuda en la obra del coro y órgano ${ }^{56}$, o los 3.000 que obtuvo el dominico fray Alvaro con objeto de colaborar en la edificación del monasterio de Santo Dómingo de Scala Coeli en Córdoba ${ }^{57}$.

Frente a este primer grupo de donativos, existe una serie de noticias que especifican un destino constructivo. Podían ser de escasa importancia como los 1.000 mrs. que se llevó el ermitaño de las Guardacabrillas (Córdoba), o más sustanciosos: el convento de Santa María la Real de Sevilla, fundado pocos años atrás, recibió en 1425100 doblas para comprar unas casas cercanas, destinadas -suponemos- a su ampliación ${ }^{58}$. Quizá los 8.600 mrs. entregados al prior de

\footnotetext{
51. IPM 1406, 259; 1417, 105; y 1422, 176.

52. IPM 1410,95 y 146 .

53. Por citar algún ejemplo IPM 1401, 9, 10 y 56; 1409, 40, 42 y 77 y muchas otras referencias.

54. IPM 1410, 76 .

55. IPM 1411, 73 y 1421, 34. Tampoco cabe esperar consecuencias artísticas de los 500 mrs. entregados a dos frailes de Santa Catalina del monte Sinaí, en dificultades por causa de guerras: $1420,99$.

56. Se entregaron por el trabajo que se había tomado un tal fray Francisco en la ciudad. Frente a ello, en 1426 se dieron 2.000 mrs. a fray Alvaro y sus acompañantes por predicar en Cuaresma: 1425,67 y 37 .

57. IPM 1424, 17.

58. IPM 1416,92 y 1425,39 .
} 
Guadalupe en 1400 sirvieran para contribuir a las obras del monasterio alzado entre 1389 y 1412, dado que consta la ampliación considerable de la iglesia en tiempos del padre Yáñez e incluso se supone una consagración en 1402 al término de las obras, lo que abundaría en el destino constructivo del donativo sevillano ${ }^{59}$. Merece ser destacada la asignación en 1348 de 200 mrs. anuales para la iglesia de Santiago de Utrera, no por lo limitado de la cantidad, sino por la razón que impulsó el donativo: al estar cerca del castillo perteneciente a la ciudad de Sevilla, en muchas ocasiones el castellano y sus soldados acudían allí a deshora a recibir sacramentos y ser enterrados ${ }^{60}$.

Hemos dejado para el final la colaboración más trascendente: a raíz de un milagro, el concejo decidió comprar la casa donde había acontecido para edificar un monasterio de monjas. Corría el año 1409 y en 1413 el convento ya llamado de Nuestra Señora del Valle obtuvo 6.000 mrs. para la adquisición de unas viviendas contiguas donde poder fundar monasterio. Por tanto, al concejo de Sevilla cabe atribuir un papel importante en su construcción, aunque parece claro que todo se hizo por mandato real, puesto que una de las tareas de las monjas era rezar por las almas de los reyes pasados y de Juan II y su familia, oraciones en las que también debían ser tenidos en cuenta los regidores de la ciudad ${ }^{61}$.

Normalmente todas estas cantidades procedían de los fondos del concejo que por mandato de los reyes debían destinarse a limosnas.

\section{Pintura y artes suntuarias}

Las noticias sobre pintura son tan buscadas como escasas. La única referencia clara alude a las diez doblas de oro con que el concejo contribuyó a la ejecución en 1425 de un retablo destinado al altar mayor del convento de San Leandro ${ }^{62}$. El resto de los documentos sólo hablan de pintores que realizan tareas que podemos considerar de menor entidad, si bien son espejo de la actividad cotidiana de los maestros. Así sabemos que el pintor Luis López decoró en 1431 los pendones

\footnotetext{
59. IPM 1400-1401, 4; L. TORRES BALBAS, Arte almohade, arte nazarí, arte mudéjar, vol. IV de la col. "Ars Hispaniae", Madrid, 1949, p. 302; F. S. GARCÍA y F. F. TRENADO: Guadalupe, historia, devoción y arte. Sevilla, 1978, p. 76.

60. IPM $1310-1376,1$ y 3 .

61. IPM 1409,18 y 19; 1412, 189, XIII; y $1413,67$.

62. IPM 1421, 24. Nada indica que el retablo sea de pintura y no de escultura. Según Ortiz de Zúñiga las monjas se habían trasladado al nuevo emplazamiento en 1369 y su iglesia estaba terminada en 1377: Anales Eclesiásticos y Seculares... de Sevilla ... corregidos por A. M. Espinosa. Madrid, 1796, t. II, p. 177. Este retablo gótico ya había sido sustituido a finales del siglo XVI por el encargado a Diego de Velasco y Jerónimo Hernández, a su vez aprovechado en parte en el que todavía hoy podemos admirar, ejecutado entre 1745 y 1748: E. VALDIVIESO y A. MORALES: Sevilla oculta. Sevilla, 1980, p. 43.
} 
de los trompetas de la ciudad, y que los 1.000 mrs. a él pagados fueron considerados cantidad adecuada en la tasación de otros dos pintores sevillanos: Alfonso García y Jácome ${ }^{63}$.

Más interesantes son las referencias a bordados. Aparte de los sobrebancales de lana bordados con las armas del rey para los asientos de la casa del cabildo ${ }^{64}$, destaca la confección de un pendón de la ciudad con las armas e imagen de San Fernando en 1407, similar al que ha llegado a nuestros días guardado en el Archivo Municipal, fechado por Gestoso en la primera mitad del siglo XV. El pendón se hizo para acompañar a las huestes sevillanas contra los moros y costó 9.177 mrs., sobrepasando por tanto el presupuesto inicial de $7.000^{65}$.

\section{Los maestros}

Todas estas noticias dispares nos permiten por otra parte conocer algo más de la vida de los maestros que en ellas intervenían. Sabemos, por ejemplo, que el salario medio rondaba los $20625 \mathrm{mrs}$. al día ${ }^{66}$, que algunos unían a su oficio algún cargo, como la guarda de la entrada del vino de la puerta de la Macarena que disfrutaba Juan Sánchez en $1417^{67}$, o que normalmente quienes tenían asignada una labor como el cuidado de caños, puertas o puentes con frecuencia realizaban otros trabajos, es decir, que sus ocupaciones no les llevaban toda la jornada ${ }^{68}$.

Como es natural, son pocos los pintores conocidos ya que pocas son las pinturas encargadas. Aparecen Luis López, Alfonso García, un tal Jácome y Pedro González ${ }^{69}$. Mayor es el número de carpinteros y sobre todo de albañiles, de los que nos vamos a ocupar con más detalle.

Ante la cincuentena de maestros albañiles que van desfilando por los documentos, lo primero que salta a la vista es su separación entre cristianos y musulmanes. Pese a lo que podría hacer pensar la impronta mudéjar en el arte sevillano, son muchos más los cristianos, en total unos treinta y cinco frente a quince

63. IPM 1430-1431, 89, 90 y 91. Otros pendones parecidos se habían hecho en 1427: 1426, 86 y 90 , y en 1407 (n. ${ }^{9} 46$ ). Otro documento menciona de pasada al pintor Pedro González en 1410: 1410,89.

64. IPM 1422, 112.

65. J. GESTOSO: Noticia histórico-descriptiva del antiguo pendón de Sevilla que se conserva en su archivo municipal. Sevilla, 1885 , p. 20 (no cita en su apéndice el documento que aludimos). F. COLLANTES DE TERÁN: El patrimonio monumental y artístico del Ayumamieno de Sevilla. Sevilla, 1970, p. 24, retrasa su datación a la segunda mitad del siglo XV.

66. IPM 1409,57 y $1419,23$.

67. IPM 1417,66 . Le suponía al menos 3.000 mrs. anuales.

68. Juan Reinel, por ejemplo, cuidaba las puertas de la ciudad y en 1417 contrató el cerramiento de la Mancebía: IPM 1417,133

69. IPM 1410,89 y 1421,91 . 
moros, proporción que todavía aumenta si quitamos los cañeros, profesión en que era reconocida la maestría de los musulmanes: nos quedamos con nueve albañiles no cañeros frente a los mismos treinta y cinco mencionados. Esto no significa ni que los cañeros moros no puedan trabajar otras labores de albañilería ni que los cristianos desconociesen el oficio de cañería, puesto que de ambas circunstancias hay ejemplos. Quizá podríamos pensar que el concejo regido por cristianos no quisiera encargar obras a moros. Con anterioridad hemos aludido a un caso en que por orden real se retiró el oficio a dos moros para dárselo a cristianos (véase obras hidráulicas), pero lo cierto es que los mismos sevillanos restituyeron en cuanto pudieron la situación anterior, nada más cesar la ordenanza impuesta por el monarca. Además, el supuesto rechazo hubiera debido aplicarse también a la arquitectura religiosa, donde parece evidente una intervención de mano de obra musulmana, aunque probablemente en menor cuantía de lo tradicionalmente admitido. Lo que no cabe dudar es que esta comparación permite confirmar una vez más que el trabajo del ladrillo y la argamasa no estaba restringido a los maestros moros y que al hablar de mudejarismo en la arquitectura debemos evitar cualquier maximalismo de raíz étnica o religiosa.

Otros datos extraemos de las relaciones de maestros. Resalta el que compongan su mayor contingente sevillanos de origen, puesto que no añaden topónimos a sus nombres salvo en tres o cuatro casos. Los apellidos repiten Fernández (cuatro), García (cuatro), González (cuatro), Martínez (seis), Rodríguez (cinco) y Sánchez (cuatro); en ciertos casos tenemos constancia de una transmisión familiar del oficio ${ }^{70}$. Entre los no sevillanos era de esperar la presencia de maestros realizando obras en lugares alejados de la capital. De cualquier modo, todos los nombres son castellanos. Por lo que hace a su distribución por la ciudad, los datos obtenidos en contadas ocasiones especifican la ubicación: además de dos trianeros aparecen vecinos de Omnium Sanctorum, San Lorenzo y San Salvador (tres). Tampoco podemos avanzar mucho sobre su condición social o los niveles del oficio. El habitual escalafón gremial puede deducirse de la situación de Pedro Fernández, quien tras ser criado de Alfonso Martínez en 1386, en 1424 obtenía la adjudicación de obras para sí mismo o en compañía de otros ${ }^{71}$. Este Alfonso Martínez (¿albañil o contratista?) es el mejor ejemplo de un personaje que solucionaba su vida con sucesivos encargos del concejo. Podríamos considerar su categoría de contratista al comprobar que recibe más obras que ningún otro, que tenía criados y que era hermano del veinticuatro Juan Martínez, armador de las

70. Al albañil Alonso Sánchez, activo en 1386, le sucede su hijo Juan Sánchez, quien ya trabaja en 1408: IPM 1386, 32 y 1408, 101. Los carpinteros Juan y Femando Reinel eran hermanos, como señalan varias noticias entre 1403 y 1413.

71. IPM 1386, 36 y 1424, 127. 
flotas reales y mayordomo de Sevilla en los años 80 del siglo XIV. Quizá simplemente fuera mejor maestro o supiera hacer más economías que sus colegas. De hecho tomó a su cargo las torres de la huerta de Goles en 1386, el adarve de Sevilla junto a la puerta de Carmona en 1408 (por $57.000 \mathrm{mrs}$.), la pared y portal de la cárcel del concejo en 1409, las quicialeras del castillo de Matrera en 1411 y el mismo año la casa de la alcaicería de la seda, la obra del castillo de Alocaz en 1412 (por 55.000 mrs.), la "necesaria" de la casa del cabildo en 1413, la pila de agua en la plaza de San Francisco en 1416, los muros cercanos a los caños de Carmona en 1419 y la alcantarilla del camino de Utrera en 1424; es dudoso que el Alfonso Martínez Carrascoso, constructor de una pared junto a la cárcel del concejo en 1430 , sea el mismo ${ }^{72}$. Una carrera completa de cuarenta años al servicio de Sevilla, respaldado por suficientes fondos como para hacerse cargo de esas obras de miles y miles de maravedíes.

Alfonso Martínez es el más destacado pero en modo alguno el único que efectúa varios trabajos sucesivos para el concejo: tenemos a Martín González reparando torres y muros en 1420 y la cárcel del concejo en $1417^{73}$; a Pedro García de Sanlúcar trabajando en el castillo de Utrera en 1419 , en el molino de la Jara en 1421 y en la casa de la alcaicería en $1429^{74}$; o a Juan Franco que obra en la cárcel en 1414, en las puertas de la ciudad en 1420, en el corral de los alcaldes en 1426 y en el adarve de Santa María del Valle el mismo año ${ }^{75}$. Terminaremos estas citas de personalidades sobresalientes con la mención de Gonzalo Fernández, adjudicatario de grandes empresas como el cauce del Tagarete en 1409, la Puente Horadada en 1416 o el puente de Eritaña en 1419, cuyos presupuestos en ocasiones rondan los $100.000 \mathrm{mrs} .{ }^{76}$; y la de un tal Diego Rodríguez, maestro mayor del rey de Castilla, que estaba en Sevilla en 1407 y difícilmente puede identificarse con el Diego Rodríguez que repara varios molinos en $1430^{77}$.

Casi las mismas afirmaciones pueden establecerse tras el examen de los carpinteros, entre los que destacan quienes ocupan puestos como maestro mayor de las atarazanas o individualidades del calibre de Alvar Sánchez, a quien siendo carpintero y albañil se adjudicaron obras en muros, puertas, molinos y casti1 los ${ }^{78}$. Tampoco aquí destacan los moros, uno frente a doce cristianos.

72. IPM 1386, 34; 1408, 71 y 101; 1411, 82 y 127; 1412, 50;1415, 118; 1416, 111 y 149;1419, 12;1424, 129; y 1430-1431, 62 .

73. IPM 1420,125 y 128, y $1417,48$.

74. IPM 1419,$60 ; 1421,110 ;$ y 1429,7 y 83 .

75. IPM 1414,$79 ; 1420,126 ;$ y 1426,93 y 96.

76. IPM 1409,$57 ; 1416,5 ;$ y $1419,10$.

77. IPM 1430-1431, 3 .

78. IPM 1425, 83, XLI y 91; 1427, 80; y 1428, 46. 
Concluiremos el apartado y con él este trabajo con una relación nominal de maestros recogidos en la documentación:

- Canteros y albañiles ${ }^{79}$ : Abdallá, Abrahem, Abrahem el Zarco, Alí el Algabeño, Diego Alonso, Cristóbal Bernal, Bucar, Diego Fernández, Gonzalo Fernández de Coria, Martín Fernández, Pedro Fernández, Juan Franco, Alfonso García de Jerez, Bartolomé García, Juan García, Juan García de Lebrija, Pedro García de Sanlúcar, Pedro Gómez, Juan García de la Cuadra, Martín González, Pedro González, Sancho González, Alí Guijarro, Fernán Gutiérrez, Hamete Agudo, Hamete de Hornachos, Fernán Ibáñez, Fernán Ibáñez de Mendoza, Mahomad el Mozo, Mahomad el Zuzy, Francisco Martín, Alfonso Martínez, Alfonso Martínez Carrascoso, Fernán Martínez, Fernán Martínez Labrador, Lope Martínez, Nicolás Martínez, Juan Martínez Cuadrado, Fernán Muñoz, Alfonso Rodríguez, Diego Rodríguez, Juan Rodríguez, Gonzalo Ruiz, Alfonso Sánchez, Juan Sánchez, Ruy Sánchez, Pedro Velázquez, Yuzaf de Niebla, Abrahem Zaba y Zaide Castellano.

- Carpinteros: Abrahem, Diego Alonso, Fernán Alonso, García Fernández, Juan Fernández, Diego López, Juan López, Bartolomé Martínez, Juan Reinel, Fernando Reinel, Antón Rodríguez, Pedro Rodríguez, Alvar Sánchez y Pedro Sotil.

79. No diferenciamos, por poder figurar indistintamente ejerciéndoles según la documentación, los oficios de cantero (aparecen específicamente como tales Diego Alonso, Juan García y Juan Sánchez), albañil y cañero. 